\title{
El fallido intento germano-otomano y la victoria británica: el tren que no llegó a Kuwait
}

\author{
The failed German-Ottoman attempt and the British victory: the train \\ that did not make it to Kuwait
}

\author{
Ricardo MÉNDEZ BAROZZI \\ Universidad Nacional de Luján
}

\section{RESUMEN}

En el contexto de la expansión imperialista de finales del siglo XIX y comienzos del siglo XX, el dominio del Golfo Pérsico representaba un punto clave para las potencias. Por esa razón, el Reino Unido se dispuso a firmar un Tratado con el emirato de Kuwait, a fin de salvaguardar sus intereses en la zona, especialmente el control marítimo hacia el Océano Indico. Al mismo tiempo, los rivales de Gran Bretaña se aprestaban a afianzar su posición en el área, siendo Francia y Rusia los primeros interesados. Sin embargo, la aparición de Alemania y su posterior alianza con el Imperio Otomano harían peligrar la hegemonía británica en la región con un ambicioso proyecto ferroviario. Se trabajará siguiendo los estudios del imperialismo decimonónico, a fin de poder describir las causas del fracaso del ambicioso proyecto.

\section{Palabras ClaVe}

Kuwait; Ferrocarril Berlín-Bagdad; Reino Unido; Alemania; Geopolítica.

\begin{abstract}
In the context of the imperialist expansion of the late $19^{\text {th }}$ and early $20^{\text {th }}$ century, control of the Persian Gulf was a key ambition for the powers involved. For this reason, the United Kingdom decided to sign a Treaty with the emirate of Kuwait in order to safeguard its interests in the area, particularly maritime control of the Indian Ocean. At the same time, the UK's rivals were preparing to consolidate their position in the zone, with France and Russia being the most important interested parties. However, the appearance of Germany and its subsequent alliance with the Ottoman Empire would endanger British hegemony in the region through an ambitious railway project. Studies of $19^{\text {th }}$ century imperialism will be used in order to describe the causes of the failure of this ambitious project failure.
\end{abstract}

\section{KEYWORDS}

Kuwait; Berlin-Baghdad Railway; United Kingdom; Germany; Geopolitics. 
La presente investigación tiene por objeto analizar las causas de la caída del proyecto ferroviario llamado Ferrocarril Berlín-Bagdad y su posterior expansión hacia el emirato de Kuwait, en el Golfo Pérsico. El propósito de este trabajo es determinar el alcance que tuvo la resistencia británica a este plan y, por otra parte, las debilidades de los alemanes y otomanos. Para ello cabe preguntarse: ¿cómo influyó la relación histórica que Kuwait mantenía con Gran Bretaña desde el S. XVIII? ¿Cuáles fueron los principales problemas financieros que debió afrontar la empresa? ¿Cuáles fueron las condiciones solicitadas por terceros países para formar parte de la misma?

\section{Materiales, métodos y estado del arte}

La metodología que guiará a la investigación estará basada en el estudio del Imperialismo de fines de siglo XIX. Concretamente se analizará la influencia que tuvieron los británicos en la región costera del Golfo Pérsico, específicamente en el emirato de Kuwait y, simultáneamente, la relación que supieron mantener los imperios alemán y otomano en el área de influencia del segundo. Asimismo, se trabajará con vasta bibliografía relacionada con la temática, además de realizar un análisis exhaustivo de numerosas fuentes oficiales.

Morris Jastraw escribe en el momento en que se producía la Primera Guerra Mundial $^{1}$. El autor analiza las causas que llevaron a la misma y señala que el conflicto por el ferrocarril al Golfo Pérsico fue una de las principales. Jastraw, historiador estadounidense de origen polaco, culpa a Alemania por el conflicto bélico, señalando que fueron sus ambiciones pangermanistas en los Balcanes y su deseo expansionista lo que LAS llevó al conflicto armado. El Asia Menor era considerada como un área clave por Berlín para expandir su influencia en Oriente Medio. Por otra parte, para los británicos era primordial retener el control de las actividades económicas en Basora, ciudad cercana al Golfo.

El diplomático argentino Eugenio Pallarés Jordá, quien escribió su ensayo sobre Kuwait mientras trabajaba como Ministro Consejero Económico y Comercial de la Embajada de su país en el Líbano, hace un valioso aporte al rastrear los primeros intentos de construir un ferrocarril que alcanzase el Golfo Pérsico en una fecha tan temprana como 1850 y un segundo intento tres décadas más tarde ${ }^{2}$. El autor señala la presión sufrida por el Gobierno británico por parte de empresarios de aquel país, para evitar que el ferrocarril fuese administrado por un consorcio extranjero.

Ya en 2001, Jonathan Mc Murray, en su obra, enfatiza varios aspectos no considerados por otros autores: el rol socioeconómico que le cupo a los trabajadores y las empresas beneficiadas con la construcción ferroviaria ${ }^{3}$. El autor describe la dimensión intercultural entre trabajadores otomanos y los representantes alemanes, lo que define como cooperación multicultural. Mc Murray afirma que, en los últimos años de su construcción, previos al estallido de la guerra, el proyecto fue más económico que estratégico.

1. Morris Jastrow, The war and the Baghdad Railway. The story of Asia Minor and its relation to the present conflict, Filadelfia, Lipincott, 1917.

2. Eugenio PALLARÉs JoRDÁ, “Emirato de Kuwait”, Publicación de la Embajada de la República Argentina en el Líbano, Beirut, Embajada Argentina en el Líbano, 1970.

3. Jonathan Mc Murray, Distant Ties: Germany, the Ottoman Empire, and the Construction of the Baghdad Railway, Westport y Londres, Praeger, 2001. 
Mustafá Bilgin habla del impacto sufrido en las relaciones anglo-otomanas debido a la construcción ferroviaria ${ }^{4}$. El autor analiza la génesis de la relación germano-otomana y los distintos acuerdos alcanzados por ambos imperios, al tiempo que crecían las sospechas en los gabinetes diplomáticos de Gran Bretaña, Rusia y Francia, señalando el dialogo entre ellos respecto a esta cuestión. Bilgin hace hincapié en la alternativa que hubiese significado la salida al Golfo por parte del ferrocarril respecto al Canal de Suez.

Por último, John Karkazis realiza un análisis detallado tanto desde el aspecto geopolítico como del geoeconómico sobre el proyecto ferroviario Berlín-Bagdad ${ }^{5}$. El autor hace una comparación sobre las crisis internacionales entre las potencias mundiales, situación que equipara al presente. Karkazis resalta que, para los otomanos, la construcción del ferrocarril significaba una alternativa muy interesante frente al transporte marítimo en la zona. El transporte ferroviario, consolidado en Europa y los Estados Unidos, desde la Segunda Revolución Industrial implicaba menores costos, más rapidez y accesibilidad a una mayor cantidad de sitios. También, el autor alude al descubrimiento de petróleo en los suelos del área a comienzos del siglo XX, lo que atrajo el interés de varias potencias europeas.

\section{La política exterior del Imperio Alemán}

En 1890, cuando el emperador alemán Guillermo II decidió despedir a Bismarck, culminaba en aquel país la llamada Realpolitik, que impulsaba la política exterior fijada en Europa. Aparecía entonces la Weltpolitik o política mundial, la cual sostenía que Alemania debía convertirse en una potencia mundial más agresiva y competir directamente con otros estados europeos, como Gran Bretaña, Francia y Rusia 6 .

La Weltpolitik fue ideal para la industria armamentística, así los fabricantes de acero se dedicaron a construir buques para la Marina, que ya competía fuertemente con la británica, en el contexto del imperialismo de finales del siglo XIX. Este crecimiento militar no estaba ligado precisamente a la adquisición de colonias, sino a alterar la balanza de poder en favor del Imperio Alemán y, por ello, en contra de Gran Bretaña ${ }^{7}$.

Desde la unificación alemana de 1871, el país creció de forma vertiginosa, superando ampliamente a Francia y luego a Gran Bretaña, convirtiéndose en la primera potencia industrial europea que, junto a los Estados Unidos, tenía la hegemonía mundial manufacturera. Este desarrollo notable llevó a pensar a muchos integrantes del gabinete imperial que el país debería convertirse también en una potencia militar ${ }^{8}$.

Entre otros proyectos de desarrollo y hegemonía mundial, los alemanes propusieron la construcción de un ferrocarril que uniese Berlín con Bagdad, realizando

4. Mustafa BILGIN, “The Construction of the Baghdad Railway and its impact on Anglo-Turkish relations, 1902-1913”, Osmanl Tarihi Araştırma ve Uygulama Merkezi Dergisi OTAM, 16 (2004), https://doi.org/10.1501/OTAM_0000000524.

5. John KARKAZIS et al., "Geo-economics vs Geo-politics: The Baghdad Railway Project and the Spoils of a Perpetual Economic War around Middle East”, Academic Journal of Interdisciplinary Studies, 8-2 (2019), https://doi.org/10.2478/ajis-2019-0032.

6. James JoLL, Historia de Europa desde 1870, Madrid, Alianza, 1983, p. 117.

7. Ibídem, p. 118.

8. Ricardo MÉNDEZ BAROzZI y Carlos OREJÓN, “El Zollverein: un paso primordial camino a la unificación alemana”, Revista Contribuciones a las Ciencias Sociales (2019), https://www.eumed.net/rev/cccss/2019/12/zollverein-unificacion-alemana.html. 
una alianza estratégica con el Imperio Otomano, aunque en realidad el proyecto era aún más largo, ya que en un primer tramo se uniría el puerto de Hamburgo con Berlín y, finalmente a Bagdad con Basora y Kuwait. Esta potencial salida de Alemania al Golfo Pérsico no solo constituía una alternativa al Canal de Suez, sino que también amenazaba directamente la ruta a la Joya de la Corona británica. Por otra parte, el diplomático y arqueólogo alemán Max von Oppenheim, mientras trabajaba en el proyecto del Ferrocarril de Bagdad en 1899 financiado por el Deutsche Bank, afirmaba que debían establecerse colonias alemanas en Oriente Medio ${ }^{9}$.

La línea ferroviaria Berlín-Bagdad buscaba el cobre de los montes Tauro, el aceite de Kirkuk, el tabaco, la lana, el algodón, el grano y los frutos de Mesopotamia y Kurdistán. Pero además de esas valiosas materias primas, Oriente Medio se constituiría en uno de los mercados más ricos del mundo para las manufacturas alemanas. Según Paul Rohrbach, uno de los más fervientes imperialistas alemanes, Inglaterra solo podía ser atacada en Egipto, ya que así no solo perdería su dominio sobre el Canal de Suez y su vínculo con la India y los mercados asiáticos, sino también sus intereses en África. La conquista debía ser hecha por el Imperio Otomano, a fin de obtener el apoyo de los súbditos musulmanes en todas partes del mundo. Para dicha conquista era clave la aparición del ferrocarril para el transporte de tropas y mercancías ${ }^{10}$.

\section{El desarrollo ferroviario en el Imperio Otomano}

Los primeros indicios de la construcción de un ferrocarril que alcanzase las costas del Golfo Pérsico datan de 1850 y 1878. En ambas ocasiones, el Gobierno británico, bajo presión de empresas privadas, había rechazado la cooperación de otros países interesados en la construcción del ferrocarril ${ }^{11}$.

Para 1888, comenzó a operar la famosa línea ferroviaria llamada Orient Express que unía a Estambul, la capital del Imperio Otomano, con París y Londres. Aquel mismo año se puso en marcha otro proyecto ferroviario liderado por un consorcio alemán llamado Anatolian Railway Company (ARC), financiado por el Deutsche Bank. El mismo estaba destinado a extender el ferrocarril en Asia Menor, llegando en 1893 a enlazar el tramo entre Haidar Passa, Nicomedia y Ankara, y completando en 1896 el trayecto entre Eski Shehir hasta Konia. También el Imperio Otomano se acercó al Austrohúngaro, con el fin de obtener apoyo para el proyecto ${ }^{12}$.

Simultáneamente, en Kuwait ocurrían sucesos importantes. En 1896, el emir Mubarak el Grande asesinó a su hermano Muhammad con apoyo británico y en detrimento de los intereses otomanos ${ }^{13}$. Para 1897, se consideró por primera vez que

9. Lothar RATHMAnN, Berlin - Bagdad. Die imperialistische Nahostpolitik des kaiserlichen Deutschlands”. Berlín, Dietz Verlag, 1962, p. 29. La afirmación de este diplomático parece contradecir el punto de vista del Sultán Abdul Hamid II, cuya postura se explica más abajo.

10. Wolfram GotTLIEB, Studies in Secret Diplomacy during the First World War, Londres, Allen \& Utwin, 1957, pp. 22-23.

11. PALLARÉS JORDÁ, “Emirato de Kuwait”, p. 8.

12. Agustín RodríGUEz GonZÁLEZ, “Antecedentes históricos y causas del conflicto”, Revista General de Marina, 267 (2014), p. 208.

13. Briton COOPER Busch, "The rise of the Kuwait question, 1896-1899” en Britain and the Persian Gulf (1894-1914), Los Angeles, Library of the Congress, 1967. 
Kuwait fuera la terminal del trayecto ${ }^{14}$. Por ello, en 1898 y 1899, representantes de los gobiernos alemán y ruso iniciaron negociaciones por primera vez con el emirato a fin de poder extender las respectivas líneas férreas ${ }^{15}$, pero la conversación terminó en un fracaso debido a la presión británica sobre el gobierno kuwaití, ya que le pidió que se negara al proyecto $^{16}$.

En 1899, el Gobierno otomano concedió a una empresa alemana el derecho de construir un ferrocarril que atravesara Asia Menor para conectar Estambul y Bagdad. El proyecto finalizó en $1903^{17}$, cuando la compañía comenzó la extensión hasta la actual capital iraquí ${ }^{18}$. La construcción del ferrocarril a Bagdad bajo las inversiones alemanas fue la principal causa de rivalidad entre los otomanos y los británicos durante las primeras décadas del siglo XX, ya que se preveía como una ruta alternativa frente al Canal de Suez ${ }^{19}$.

Desde aquel momento, y hasta el estallido de la Gran Guerra, este propósito se había convertido en el fantasma del siglo $X X$, omnipresente en las tensiones entre Alemania y las otras potencias europeas ${ }^{20}$. Por otra parte, para el Imperio Otomano representaba la posibilidad de movilizar sus fuerzas de una manera rápida y eficaz hacia sitios difíciles de llegar, como Arabia, Irak y Siria ${ }^{21}$.

En 1899, el emir de Kuwait Mubarak el Grande firmó un tratado con Gran Bretaña, nación que tenía una enorme influencia en el Golfo desde mediados del s. $\mathrm{XVIII}^{22}$. Mubarak tenía sospechas de la anexión plena del emirato por parte de los otomanos, quienes gobernaban aquella zona solamente de facto. Los británicos, comenzaron entonces a reforzar su presencia en el área a fin de proteger su influencia económica y geopolítica. Posteriormente, Londres enviaría a su representante, el primer

Agente Político destinado a la región, el mayor Stuart Knox, quien había sido parte del Gobierno de la India, a fin de que asesorase al emir sobre distintos asuntos ${ }^{23}$.

En 1900 llegó al Golfo un enviado del gobierno alemán llamado Stermrich encabezando una misión que pretendía realizar la construcción de dicho ferrocarril, lo que

14. Carl Jones, “Carlcymru’s History Blog”, 18-4-2014, The Berlin Baghdad Railway and the outbreak of World War I, https://carlcymrushistoryblog.wordpress.com/2014/04/18/the-berlin-baghdad-railway-andthe-outbreak-of-world-war-one/ (consulta 27-9-2020).

15. Según Carl JonEs, los rusos contaban con un ferrocarril que atravesaba Persia y también pretendía finalizar su recorrido en algún punto del Golfo Pérsico, debido a este interés en la zona, Rusia rivalizaba con Gran Bretaña.

16. PALlarÉs JORDÁ, “Emirato de Kuwait”, p. 8.

17. En esta fecha se creó otra empresa, la Baghdad Railway Company (BRC) que sustituyó a la ARC.

18. KARKAZIS, et al., “Geo-economics vs Geo-politics”, p. 210.

19. GLOBAL SECURITY ORG., Berlin-Baghdad Bahn / Berlin-Baghdad Railway, https://www.globalsecurity.org/military/world/europe/de-berlin-baghdad.htm (consulta 26-9-2020).

20. JASTROW, The war and the Baghdad Railway, p. 9.

21. Sean Mc MeEkin, The Berlin-Baghdad Express: The Ottoman Empire's and Germany's bid for World Power, Cambridge, The Belknap Press, 2010, p. 51.

22. Ricardo Méndez BAROzZI, “La creación del Emirato de Kuwait”, Actas de las XVI Jornadas Interescuelas/Departamentos de Historia. Departamento de Historia. Facultad Humanidades, Mar del Plata, Universidad Nacional de Mar del Plata, 2017, p. 4.

23. Ricardo Méndez BAROzzI, "Las perlas en el emirato de Kuwait y la formación de los sectores burgueses”, en Posición, 3 (2020), p. 5. 
fue rechazado por el jeque Mubarak, quien luego del Tratado firmado en 1899 defendía a rajatabla los intereses británicos ${ }^{24}$. El programa ferroviario no solo aumentó las tensiones en la zona, sino que también cambió la atención de las grandes potencias, las cuales dejaron de focalizar sus objetivos en Europa para pasar a Mesopotamia. Por ello, se sostiene la hipótesis que este conflicto fue una de las principales causas que derivó en el desencadenamiento de la Primera Guerra Mundial ${ }^{25}$.

\section{La influencia geopolítica y geoeconómica en la zona}

Las relaciones fluidas entre los imperio alemán y otomano habían comenzado con actividades culturales en 1880. Mientras tanto, los intereses franco-británicos en la región habían decaído bastante durante la década de 1870. Gran Bretaña había realizado un cambio de política en la zona al no entrometerse en el conflicto ruso-otomano de 1877, a diferencia de lo sucedido en Crimea dos décadas antes. Durante la década de 1880, Alemania se ocupó de capacitar a los oficiales turcos; por otra parte, los alemanes financiaron varios proyectos de los otomanos, lo que hizo que la relación entre ambos imperios creciera rápidamente ${ }^{26}$.

El sultán Abdul Hamid II cuenta en sus memorias que Alemania era un país menos peligroso que Gran Bretaña, Francia y Rusia. Ello se debía a que aquel país solo tenía intereses comerciales en Medio Oriente y no buscaba ganancias políticas ni territoriales ${ }^{27}$. Sin embargo, el Foreign Office contradecía estas afirmaciones al informar que Alemania estaba buscando algún tipo de expansión política bajo el disfraz de desarrollo económico en la Turquía asiática ${ }^{28}$. Más allá de estas posiciones encontradas, parece claro que la presencia alemana en territorio otomano se debía mayormente al objetivo de obstaculizar la ruta a la India, la mayor preocupación de los británicos, en un momento de álgida rivalidad entre ambas potencias. Asimismo, los turcos buscaban extender el ferrocarril para tratar de reemplazar al transporte marítimo en la zona ${ }^{29}$.

El Imperio Alemán ganó rápidamente una enorme influencia en la Puerta Otomana $^{30}$, lo que le permitió ingresar al mercado de Oriente Medio de forma acelerada. En 1888, se comenzó a construir una línea ferroviaria con el objeto de unir a Berlín con Bagdad. Este proyecto encendió las alarmas en Francia y en Rusia. Gran Bretaña no se opuso en principio a este propósito, con la condición de que el capital de aquel país sería invitado a participar de la empresa.

El nuevo plan ferroviario incluía una extensión hasta Basora y la salida al Golfo. Era considerado el segundo gran proyecto de la zona, luego del canal de Suez, y para los otomanos tenía una gran importancia comercial y estratégica ${ }^{31}$. Para 1901, los alemanes

24. Gupta ChHABRA, Advanced study in the History of Modern India, vol.2, 1813-1920, Nueva Delhi, Lotus, 2005, pp. 521-526.

25. BILGIN, "The Construction of the Baghdad Railway”, p.113.

26. Ibídem, pp. 114-118.

27. Sultán Abdul Hamid II, Siyasi Hatiratim, Estambul, Dergah Yay, 1987, pp.115, 137 y 153.

28. FOREIGN OFFICE HANDBOOK, febrero 1919, FO 373/5/2, pp. 25, 32 y 56.

29. KARKAZIS et al., “Geo-economics vs Geo-politics”, p. 216.

30. Nombre dado al Imperio otomano en el contexto diplomático.

31. BILGIN, "The Construction of the Baghdad Railway and its impact on Anglo-Turkish relations, 19021913”, pp. 113-128. 
ya sabían de la existencia de una extensa área de riquezas petroleras en la zona situada entre los ríos Éufrates y Tigris; por ello, las barreras de todo tipo por parte de las potencias europeas comenzaron a aparecer. En cuanto a la financiación, Francia tomó una pequeña participación en el BRC y Rusia declinó ser parte del proyecto ${ }^{32}$.

Figura 1: Imagen del Ferrocarril de Bagdad en la década de 1900

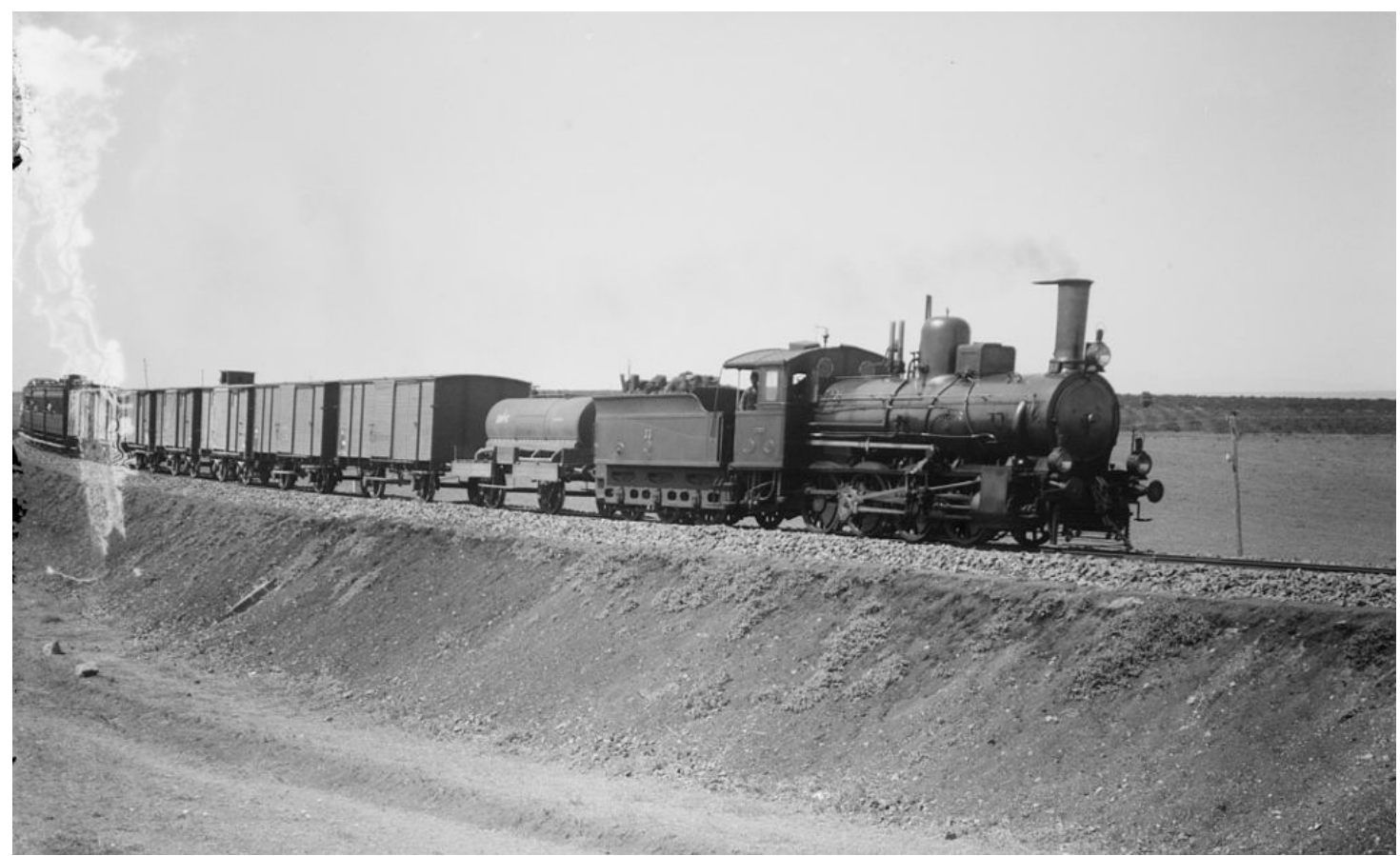

F.: Eric and Edith Matson Photograph Collection, https://loc.gov/pictures/resource/matpc.04665/ (consulta: 27-9-2020).

\section{La lucha por la hegemonía política}

Los británicos comenzaron a preocuparse en 1902, cuando se estableció que el fin de la línea sería algún punto del Golfo Pérsico a determinar entre el Gobierno otomano y la empresa constructora alemana. En 1904, un informe del Virreinato de la India ${ }^{33}$ aseguraba que los ingenieros alemanes pensaban que el ferrocarril podría llegar a la isla de Bubiyan, a unos pocos kilómetros de la ciudad de Al-Kuwait, territorio en el cual los otomanos habían establecido una base militar en $1902^{34}$. Esta situación fue considerada como peligrosa para los intereses británicos y para el emir kuwaití, quien emitió una queja formal $^{35}$. Cómo se explica más abajo, existían varias alternativas para la nueva terminal en el Golfo Pérsico, como las ciudades iraquíes de Al-Fao y Basora, además de la mencionada ciudad de Al-Kuwait y la isla de Bubiyan.

Si el ferrocarril lograba extenderse desde Bagdad a Kuwait, significaría la ruta más rápida y económica que podía unir al Golfo, los pozos petroleros y Berlín, además

32. KARKAZIS et al., “Geo-economics vs Geo-politics”, p. 211.

33. Collection of papers respecting the attitude of HMG about the Baghdad Railway and the purchase of Land at Kuwait, Sadawi, "Government of India, Fort William, to Secretary, Broderick, 4 February 1904”, FO881/9055X, p. 123.

34. JASTROW afirma que otra alternativa era la ciudad iraquí de Al-Fao. Esta ciudad se encuentra en la península homónima, en el actual sur de Irak, cercana al río Shatt al-Arab y al Golfo Pérsico.

35. BILGIN, “The Construction of the Baghdad Railway”, pp. 119-120. 
de la salida al Mar del Norte mediante el puerto de Hamburgo, causando de esta forma un notorio daño en la posición estratégica de Gran Bretaña. Por otra parte, los alemanes podían aliarse con los rusos quienes de esta forma saldrían de la Entente Cordiale que integraban junto a franceses y británicos ${ }^{36}$.

Figura 2: Mapa mostrando el proyecto ferroviario Hamburgo-Basora.

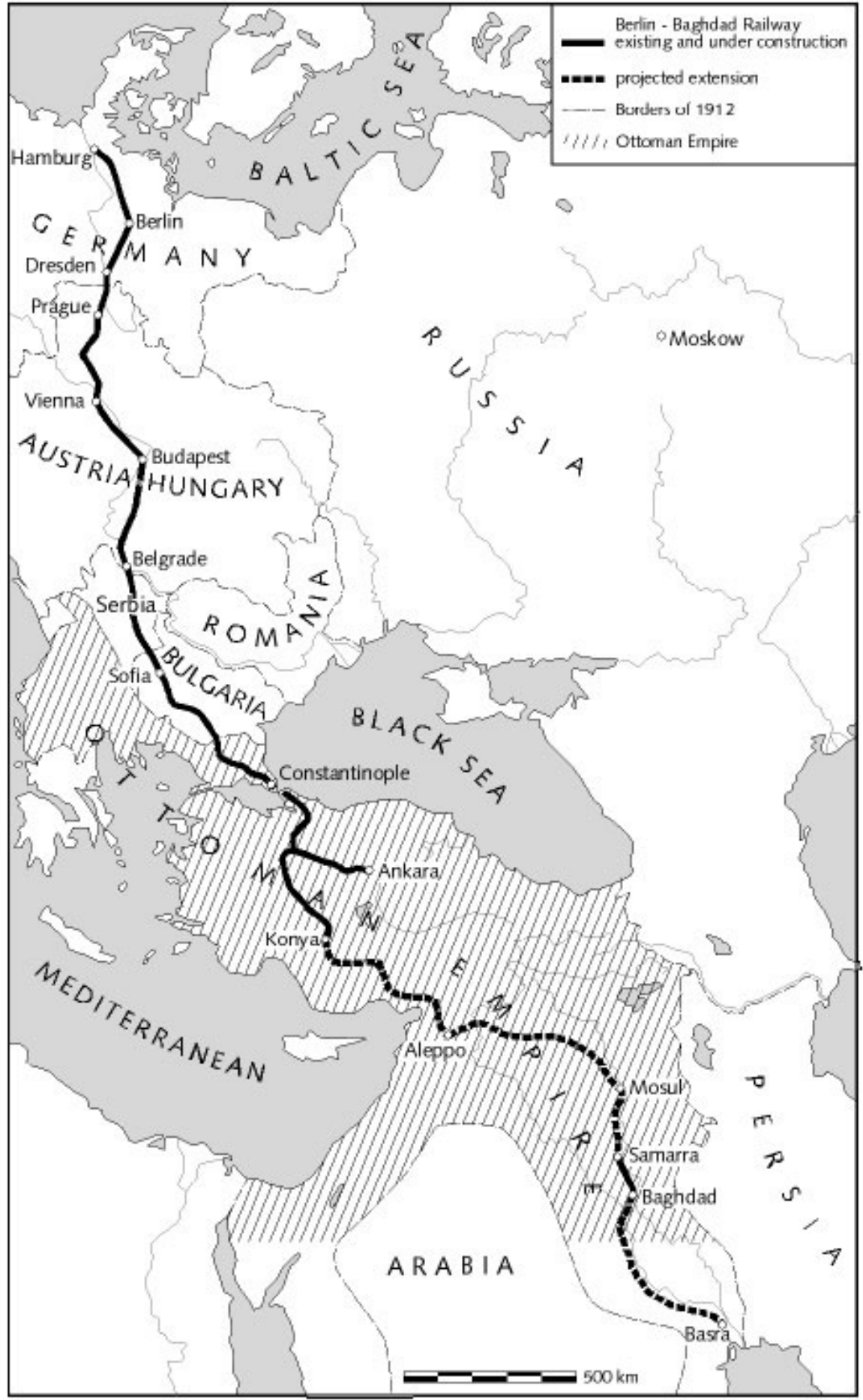

F.: Archaeoplan, https://www.archaeoplan.com.

36. JonEs, The Berlin Baghdad Railway. 
Para esta época, también se llevó a cabo la construcción del llamado Ferrocarril del Hiyaz, que unía a las ciudades de Damasco y Medina, cuyo objetivo final era la ciudad de Aqaba, en la actual Jordania, un puerto estratégico con salida al Mar Rojo, considerado otro paso clave similar a Kuwait. Esta obra también era financiada por capitales alemanes y era otra pieza clave en el desarrollo de las comunicaciones dentro del Imperio Otomano, al tiempo que, para los británicos, era considerada como otra grave amenaza para sus intereses. A pesar de la tensión entre alemanes y británicos, existía un intercambio cordial de notas diplomáticas. También hubo otro fallido proyecto de realizar un ferrocarril a Yemen, tanto por los alemanes como por los franceses ${ }^{37}$.

En 1902, la recesión económica golpeó de forma dura a Alemania, por lo que este país se vio en condiciones desfavorables para continuar apoyando unilateralmente el proyecto. Por ello, el Deutsche Bank firmó un acuerdo con la Baghdad Railway Company $(B R C)^{38}$, en cooperación con la ARC, un contrato de 99 años de duración a partir de 1903 por el cual los concesionarios estarían obligados a concluir la extensión ferroviaria hasta el Golfo Pérsico para $1911^{39}$.

La primera reacción fue la de George Hamilton, secretario de Estado del Virreinato de la India, quien envió un telegrama al virrey manifestando que era peligroso inmiscuirse en los movimientos de las tropas otomanas en tierras que Kuwait consideraba como propias, pero que para el emirato era difícil de probar. Hamilton afirmaba que no deseaba obstruir la extensión del ramal ferroviario desde Bagdad, fuera al Golfo o a Kuwait, pero esta situación no fue tenida en cuenta por los británicos ${ }^{40}$.

En 1907, el Foreign Office comunicó a los embajadores de Rusia y Francia el punto de vista del Gobierno británico respecto a la extensión del Ferrocarril de Bagdad, explicando que el Reino Unido solo aceptaría participar en el esquema ferroviario si este se adaptaba a un sistema de control internacional ${ }^{41}$. La política británica respecto de esta cuestión parece haber sido muy cautelosa frente a sus aliados de la Entente, no oponiéndose de forma directa al proyecto, sino proponiendo medidas difíciles de llevar a cabo en el clima tenso que se vivía, previo a la Gran Guerra.

De hecho, tanto el Gobierno otomano como el alemán habían realizado intentos para llegar a un acuerdo con Gran Bretaña, pero esto no había sido posible. El punto de fricción estaba en la internacionalización de la línea, asunto que enfatizaba el Gobierno británico, mientras que los otros dos lo rechazaban. Esta situación llevaría al mencionado aumento de la tensión en la zona y a la atención de las demás potencias europeas. Los británicos intentaban sostener el statu quo en la zona y evitar el dominio alemán ${ }^{42}$.

37. ÖZYÜKSEL, The Hejaz railway and the Ottoman Empire: Modernity, Industrialisation and Ottoman Decline. Middle Eastern Studies. Londres Tauris, 2014, pp. 144-147, 175-176.

38. Esta compañía estaba dominada por el Deutsche Bank y otros intereses alemanes.

39. KARKAZIS et al., “Geo-economics vs Geo-politics”, p. 211.

40. "Collection of papers respecting the attitude of HMG in regard to the Baghdad Railway and the purchase of Land at Kuwait; Sadawi”, Government of India, Fort William, to Secretary, Broderick, 4-2-1904, FO 881/9055X: ibídem, p.123.

41. BILGIN, “The Construction of the Baghdad Railway”, pp. 120-121.

42. Ibídem, pp. 121-122. 
Figura 3: Mapa mostrando el proyecto de Ferrocarril a Kuwait en la zona otomana

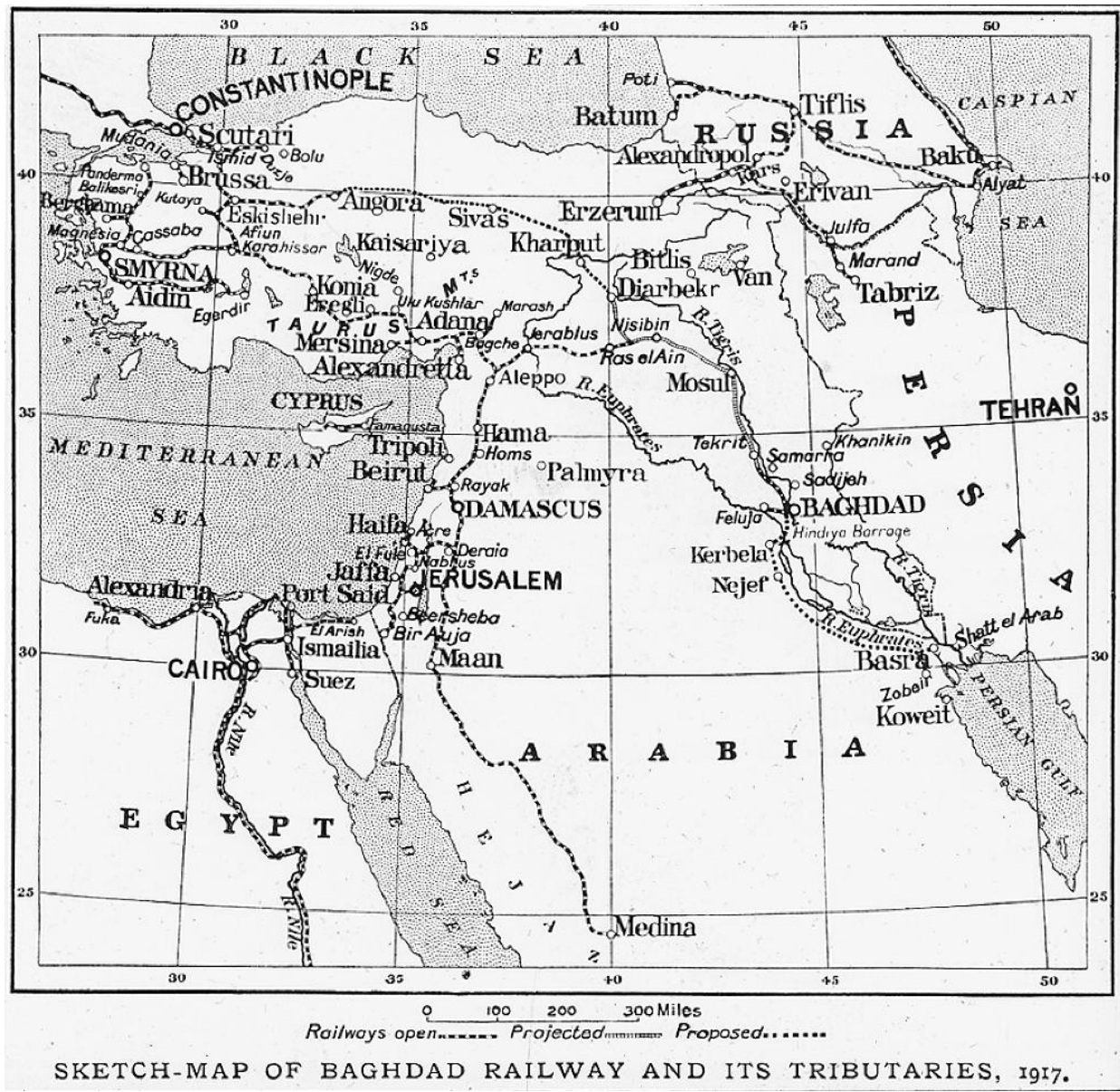

F.: NEW YORK STATE ARCHIVES, Berlin-Baghdad Railway, http://www.archives.nysed.gov/education/berlin-baghdad-railway-1917 (consulta: 21-9-2020).

1917 ,

\section{Convulsiones internas y externas que afectaron al proyecto}

El acceso al poder de los Jóvenes Turcos el 23 de julio de 1908 forzó al sultán Abdul Hamid II a restaurar la Constitución de 1876, la cual fue abolida al entrar en conflicto el Imperio con Rusia al año siguiente. El sultán era una persona flexible, habituada a lograr acuerdos políticos con todas las potencias. En el momento de la llegada al poder del nuevo movimiento, la extensión del ferrocarril se encontraba a la altura de los Montes Tauro, en la actual Turquía, un punto muy complejo para realizar el trazado de vías.

Como consecuencia de la inestable situación política interna, el programa ferroviario entró en una pausa. Para finales de 1908, comenzó a operar el Parlamento, en donde aparecieron voces opuestas al Ferrocarril de Bagdad, considerando al proyecto como monstruoso y corrupto ${ }^{43}$. El 27 de abril de 1909, los Jóvenes Turcos depusieron al sultán luego de un fallido intento de golpe de Estado.

Por su parte, el Foreign Office vio con simpatía al nuevo régimen, pero no firmó ningún tipo de alianza ${ }^{44}$. Esta situación marca la desconfianza que tenía el Reino Unido

43. Karkazis et. al "Geo-economics vs Geo-politics”, pp. 213-214.

44. BILGIN, “The Construction of the Baghdad Railway”, pp. 122-123. 
respecto a Estambul, al que seguía viendo como un aliado clave de Berlín. Al mismo tiempo, los inversores alemanes debieron recurrir a Londres para poder continuar con la financiación del proyecto. El nuevo Gobierno otomano intentó sacar ventaja de la rivalidad entre las potencias, pero paradójicamente esto llevó a la disolución y distribución de vastos territorios de su Imperio ${ }^{45}$, con la firma del Tratado Sykes-Picot de 1916, que establecía el reparto de territorios otomanos entre Gran Bretaña y Francia luego de la Gran Guerra.

A mediados de 1910, Javid Bey, el ministro de Finanzas otomano, viajó a París y Londres con el objeto de obtener recursos para la extensión del ferrocarril y otras empresas, pero no obtuvo los resultados esperados; sin embargo, el apoyo monetario fue concedido por Alemania ${ }^{46}$. Al llegar a Gran Bretaña, el Foreign Office le informó que ese proyecto ferroviario constituía una amenaza para el comercio británico en la región, por lo que ponía como condición a los otomanos que los británicos tuvieran el 55\% de las acciones de la empresa ferroviaria en la parte en que ésta atravesaba el Golfo. El otro punto de disenso fue Kuwait, ya que los otomanos querían recuperar su influencia allí, algo que era rechazado tajantemente por Londres ${ }^{47}$.

Según el embajador británico en Estambul, Sir Gerard Lowther, la comunidad judía local tenía una importante presencia en el Gobierno otomano. El diplomático consideraba que esto se debía a una débil posición británica en la Mesopotamia, en donde se deseaba establecer un Estado Judío autónomo, evento que ocurriría finalmente en 1948, con la conformación del Estado de Israel ${ }^{48}$.

Posteriormente al intento negociador fallido realizado en 1911, los otomanos intentaron nuevamente acercarse a Francia y Gran Bretaña en busca de apoyo económico para el proyecto de extensión de las vías férreas, proponiendo que el Gobierno turco aportara el 40\% de los gastos, mientras que Alemania, Francia y Gran Bretaña aportarían $20 \%$ cada uno. Sin embargo, esto fue rechazado por los británicos, quienes reiteraron que deseaban la posesión del 55\% de las acciones, lo que llevó el encuentro al fracaso ${ }^{49}$.

El Ferrocarril de Bagdad, como lo llamaban los británicos, constituía un punto de salvaguarda para los intereses políticos y económicos de Londres en la zona. La supremacía de Gran Bretaña estaba garantizada si se tenía el poder sobre la línea ferroviaria que unía Bagdad con el Golfo Pérsico. Además, se quería alejar a la influencia otomana de otros territorios que le pertenecían de facto, como Qatar y Bahréin ${ }^{50}$.

Para los británicos, sus intereses estaban siendo amenazados por un sistema monopólico ferroviario realizado por los alemanes, ya que los otomanos habían recurrido a Alemania para poder concluir la empresa, pero como esta no había podido ser finalizada, los otomanos tenían ahora algo que ofrecer a Gran Bretaña, a cambio de lo cual se esperaba que este país consintiera en aumentar las aduanas y aportara económicamente

45. KARKAZIS et al., "Geo-economics vs Geo-politics”, p. 214.

46. El ministro intentaba conseguir unos 30 millones de dólares.

47. BILGIN, “The Construction of the Baghdad Railway”, pp. 122-123.

48. IBÍDEM, pp. 123-124.

49. IBÍDEM, p. 124.

50. IBÍDEM, p. 125.

Rubrica Contemporanea, vol. X, n. 20, 2021 
para la construcción del ferrocarril. Las aduanas junto al control de Kuwait habían sido la palanca con la que se empezaban a ver las posibilidades de éxito para Estambul ${ }^{51}$.

Figura 4: Mapa en donde se aprecia la cercanía entre las ciudades de Basora, Al-Fao y Kuwait, fallidas candidatas a ser las terminales del proyecto ferroviario

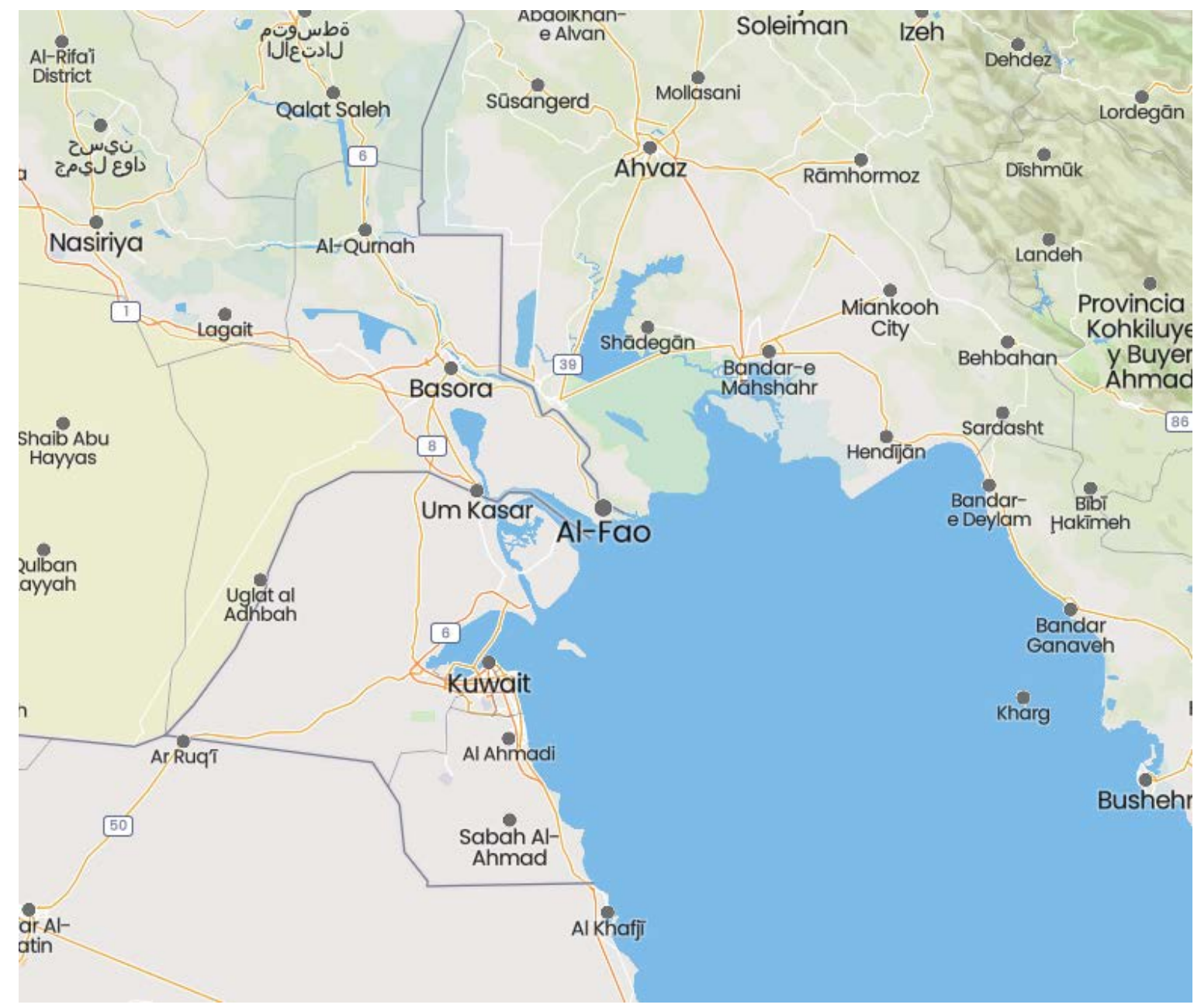

F.: https://mapcarta.com/es/12544570 (consulta: 4-3-2021).

\section{El aumento de la tensión diplomática y la interrupción del proyecto}

El intento otomano de acercarse al Golfo fue un punto de suspicacia entre las grandes potencias. Para mayo de 1911, el canciller francés le manifestó al embajador británico en su país su preocupación por la colaboración creciente entre los alemanes y los turcos y la influencia teutona en la zona. Aquel mismo año, la BRC propuso un nudo ferroviario entre Alejandreta y Alepo, el cual serviría para apuntalar el comercio en el norte de Siria y el norte del valle mesopotámico.

Esta situación causó el rechazo de Gran Bretaña, ya que así los otomanos aumentarían sus aranceles, lo que perjudicaría sus intereses considerando la cercanía entre

51. "Minute signed by various officials at the Foreign Office”, 27-3-1911, FO 371/1233, Goochand Temperly, p. 36. 
el ferrocarril y los pozos petroleros de Persia, donde los británicos habían realizado grandes inversiones, por lo que se consideraba la extensión ferroviaria como una amenaza, no solo a la mencionada ruta a la India, sino también a la logística del crudo ${ }^{52}$.

Al mismo tiempo, los reclamos británicos eran rechazados por Alemania, si bien los otomanos, en su búsqueda del apoyo británico, habían logrado la renuncia del acuerdo de 1903 por parte de Berlín en lo relativo a la línea que unía a Bagdad con el Golfo. Los alemanes habían aceptado esta propuesta con la condición de que ninguna tercera parte aportase más capital que ellos mismos. Para Alemania, los Balcanes y el Puente de Estambul eran su puerta de entrada de expansión económica, donde encontraría nuevos mercados $^{53}$.

Otros problemas, causados por terceros, afectaron al proyecto. En septiembre de 1911 y mayo de 1912, los italianos invadieron y se anexionaron Libia y las islas del Dodecaneso, lo que causó la guerra entre Italia y el Imperio Otomano ${ }^{54}$. Además, entre octubre de 1912 y mayo de 1913 se va a desarrollar la Primera Guerra de los Balcanes, en la cual los otomanos vuelven a ser derrotados por una coalición de tropas de Serbia, Montenegro, Bulgaria y Grecia ${ }^{55}$.

En 1911, Alemania firmó un Tratado con Rusia por el cual, la primera reconocía el derecho a construir el ferrocarril en Irán y los rusos se comprometían a aceptar el proyecto del Ferrocarril de Bagdad ${ }^{56}$. Por el lado otomano, el fracaso de las negociaciones ante franceses y británicos, trajo de nuevo a la influencia alemana. La presencia germánica era importante en el Ejército Turco para 1913, cuando los generales alemanes comandaban, en algunos casos a las tropas y, también lo era en asuntos económicos ya que volvía a ser el principal país financiador.

También para 1913, los otomanos, en el contexto del Tratado Anglo-otomano de aquel año ${ }^{57}$, alcanzaron un acuerdo con Gran Bretaña sobre el ferrocarril. Se admitió a dos representantes británicos en la empresa y se acordó que el final del recorrido fuera Basora, abandonándose así definitivamente la idea de la extensión al Golfo. Este tratado fue seguido por otro similar firmado entre Gran Bretaña y Alemania en junio de $1914^{58}$.

Estratégicamente hablando, la zona que pensaba cruzar el Ferrocarril de Bagdad y su salida al Golfo Pérsico representaba tocar varios de los puntos más importantes del

52. KARKAZIS et al., “Geo-economics vs Geo-politics”, pp. 213-214.

53. BILGIN, “The Construction of the Baghdad Railway”, pp. 126-127.

54. No era un dato menor el doble juego en la política exterior italiana, ya que si bien ese país tenía una alianza con Alemania y el imperio Austrohúngaro, con este conflicto perjudicó los intereses de su aliada. En 1902, Italia y Francia, enemiga de Alemania, firmaron un pacto secreto, en el que se comprometían a respetar sus respectivas áreas de influencia en el Mediterráneo y no se enfrentarían en un futuro conflicto, lo que sucedería en 1914, al estallar al Primera Guerra Mundial. Véase Matteo TOMASONI, "Italia en la periferia del Mediterráneo. Las relaciones ítalo-españolas entre los siglos XIX y XX: Política, Economía y Sociedad”, en Zibaldone, Estudios Italianos, 3 (2014), pp. 22-23.

55. KARKAZIS et al., “Geo-economics vs Geo-politics”, p. 214.

56. Murat ÖZYÜKSEL, The Berlin-Baghdad Railway and the Ottoman Empire. Industrialisation, Imperial Germany and the Middle East, Londres, Tauris, 2016, p. 172.

57. Este Tratado definió los límites del Imperio Otomano en el Golfo Pérsico respecto a Kuwait, Bahréin, Qatar y Shatt-al Arab (José AcOSTA EsTÉVEZ, La crisis de Irak-Kuwait: responsabilidad de Irak y respuesta internacional, Barcelona, PPU, 1994, p. 36).

58. BILGIN, “The Construction of the Baghdad Railway”, pp. 127-128. 
globo, tales como Estambul, Esmirna y Kuwait, los cuales tenían posiciones clave similares a las de Panamá, Gibraltar y Suez. Por otra parte, las potencias europeas consideraban a las tierras otomanas como notables proveedoras de diferentes recursos y materias primas. Si bien el territorio era muy subdesarrollado a comienzos del siglo XX, prometía tener un gran potencial $^{59}$.

Asimismo, el control político alemán sobre Serbia y Bulgaria era esencial para la realización del proyecto ferroviario, ya que serían afectadas buena parte de sus territorios, lo que le daba una dimensión considerable al proyecto pangermánico. Dicho proyecto contemplaba la unión entre Estambul y Bagdad y, desde ese punto, alcanzar Basora y el Golfo Pérsico. Al mismo tiempo, se apreciaba la decadencia del Imperio Otomano, ya que éste le estaba entregando ese punto estratégico a los europeos. Alemania se enfrentaba a los integrantes de la Entente por una cuestión de supremacía en la región. Asia Menor era considerada como el hinterland de Egipto, el Levante y la Mesopotamia ${ }^{60}$.

El ambicioso proyecto pretendía unir a Hamburgo con el Golfo Pérsico en siete u ocho días y con cuatro días adicionales viajando en barco se podía llegar a la India, lo que comprometía fuertemente los intereses británicos, situación que fue exaltada por los pangermanistas en Alemania, quienes pretendían la expansión de su país en Asia Menor. Esta fue una de las razones que llevó a los británicos a establecer un protectorado en Kuwait, aprovechándose de la debilidad otomana en la zona ${ }^{61}$.

El Foreign Office había proclamado en 1902 que los alemanes no llegarían al Golfo y se mantendría el status quo, dado que, si el ferrocarril llegara a Basora, amenazaría de una forma considerable a los comerciantes británicos. El error grave que cometió Alemania fue concebir la idea de dominio de la totalidad del Asia Menor, reabriendo el paso de Cercano Oriente a Occidente. Si el ferrocarril de Bagdad en manos alemanas se hubiera extendido desde Estambul hasta el Golfo Pérsico, hubiera significado un cierre al acceso de las otras potencias europeas tan efectivo como la toma de Constantinopla por los otomanos en $1453^{62}$.

De acuerdo a la convención de 1902-1903, el ferrocarril sería usado por el Gobierno otomano con fines militares y los alemanes tendrían el derecho a construir estaciones militares a lo largo del camino, pero considerando el tutelaje que tenía el ejército teutón sobre el turco, Alemania tendría derechos de explotación sobre las tierras de Oriente. Esta situación hubiera derivado en que la Mesopotamia, Siria, Palestina y Egipto estuviesen bajo influencia germánica ${ }^{63}$.

Al estallar la Primera Guerra Mundial, el ferrocarril se encontraba distante 960 kilómetros de su objetivo inicial de llegar a Bagdad. En 1912, la cantidad de trabajadores involucrada en el proyecto alcanzaba los 15.700, lo que tuvo un destacado impacto socioeconómico en la zona, ya que surgieron nuevos poblados en relación a la empresa, con la aparición de bares, tabernas, gramófonos e incluso salas cinematográficas. En este periodo previo a la guerra, con el nuevo Gobierno otomano, el tren se había convertido

59. KARKAZIS et al., “Geo-economics vs Geo-politics”, pp. 214-215.

60. JASTROW, The war and the Baghdad Railway, pp. 3, 28 y 30.

61. Ibídem, pp. 96-97 y 99.

62. Ibídem, p. 121.

63. JASTROw, The war and the Baghdad Railway, pp. 133-134. 
en una empresa más comercial que estratégica ${ }^{64}$. Para 1914, la inversión realizada por los alemanes alcanzaba los 80 millones de dólares ${ }^{65}$.

Finalmente, este tramo se construyó durante la década de 1930 y la primera formación que realizó el trayecto entre Estambul y la actual capital iraquí se realizó en 1940, durante la Segunda Guerra Mundial. El tramo de salida al Golfo Pérsico que terminara en Kuwait o en algún otro punto cercano nunca fue concluido y de esta forma se plasmó la victoria de los intereses británicos ${ }^{66}$.

Cabe preguntarse si el Gobierno británico hubiese aceptado la construcción del ferrocarril en el caso que las empresas alemanas hubiesen mostrado una mayor solvencia o se hubiera aceptado el 55\% de participación del Reino Unido en el proyecto. Es probable que, de haber sido así, desde Londres se hubiera gestado otra maniobra de oposición a la empresa, ya que ésta afectaba directamente a uno de los puntos estratégicos para el Imperio Británico, que era el control que tenía de forma exclusiva sobre el Golfo Pérsico, relegando a las otras potencias europeas. Gran Bretaña era parte de la Entente Cordiale, opositora a la Triple Alianza, por lo cual Alemania era una potencia rival con la cual competía en muchos aspectos, así que todo parece indicar que esa sociedad hubiese resultado imposible.

\section{Consideraciones finales}

El proyecto alemán de unir a Berlín con Bagdad era ambicioso, pero sus gastos económicos parecen no haber sido previstos adecuadamente, considerando además que el Imperio Otomano necesitaba del financiamiento para poder concluirlo. Al mismo tiempo, la posición británica fue oscilante de acuerdo al contexto en el que se desarrollaban los acontecimientos. En un principio, el Reino Unido se mostró de acuerdo, ya que muchos actores, como el funcionario Joseph Chamberlain ${ }^{67}$, propulsaban una alianza germano-británica que también incluiría a los Estados Unidos. Sin embargo, la rivalidad naval y el conflicto de intereses, sumado a la búsqueda de aliados para un futuro enfrentamiento armado entre las potencias, llevó a exacerbar la rivalidad entre Berlín y Londres.

Por otra parte, Gran Bretaña que en un primer momento pareció acceder a formar parte del proyecto, nunca olvidó que su principal objetivo era la protección de la ruta que llevaba a la India, lo cual le había hecho realizar numerosas alianzas con los poderes locales. Para este trabajo, se destaca la relación que el Reino Unido supo tejer con los emires kuwaitíes desde mediados del siglo XVIII que luego se convirtió en un Tratado en 1899, luego que el jeque Mubarak el Grande accediera posteriormente al poder. Este pacto convertía al emirato en un protectorado dependiente de los británicos quienes a su vez asistirían económica y estratégicamente a Kuwait.

Otro dato importante a considerar, es la posición tomada por las restantes potencias. Rusia se negó desde un principio a ser accionista en la nueva empresa ferroviaria, ya que temía que, si las vías llegaran al Golfo Pérsico, sus intereses en Persia

64. MC Murray, Distant Ties, pp. 85-88.

65. JONES, The Berlin Baghdad Railway.

66. MC Murray, Distant Ties, p. 2.

67. JoLL, Historia de Europa desde 1870, pp. 123-124. 
se verían afectados en gran manera. Francia, por su parte, participó al principio con un pequeño capital, pero siempre mostró una gran desconfianza, ya que detrás de la construcción estaba Alemania, su enemiga natural de 1871, con la cual volvería a enfrentarse en la Primera Guerra Mundial. Los franceses también rivalizaban con los británicos en la zona por el sultanato de Omán.

La insuficiente solvencia de las empresas alemanas y el golpe de Estado que terminó con el poder del sultán Abdul Hamid II parecen haber sido las causas del fracaso. Sin embargo, también deben contemplarse la alianza franco-rusa, la anexión de Libia y consecuente guerra con los otomanos por parte de Italia, que era aliada de Alemania, sumada a otra guerra que Estambul debió afrontar con los estados balcánicos. Todo ello hizo que el proyecto fracasase, dándole de esta manera la victoria estratégica al Reino Unido, que pudo mantener el statu quo en la zona. 